\title{
Visualization of interaction between inorganic nanoparticles and bacteria or fungi
}

\author{
This article was published in the following Dove Press journal: \\ International Journal of Nanomedicine \\ 2 December 2010 \\ Number of times this article has been viewed
}

\author{
André Chwalibog' \\ Ewa Sawosz ${ }^{2}$ \\ Anna Hotowy' \\ Jacek Szeliga ${ }^{2}$ \\ Stanislaw Mitura ${ }^{3}$ \\ Katarzyna Mitura ${ }^{3}$ \\ Marta Grodzik ${ }^{2}$ \\ Piotr Orlowski \\ Aleksandra Sokolowska ${ }^{4}$ \\ 'University of Copenhagen, \\ Copenhagen, Denmark; ' $W a r s a w$ \\ University of Life Sciences, Warsaw, \\ Poland; ${ }^{3}$ Technical University of Łódź, \\ Łódź, Poland; ${ }^{4}$ Warsaw University of \\ Technology, Warsaw, Poland
}

Purpose: The objective of the present investigation was to evaluate the morphologic characteristics of self-assemblies of diamond (nano-D), silver (nano-Ag), gold (nano-Au), and platinum (nano-Pt) nanoparticles with Staphylococcus aureus (bacteria) and Candida albicans (fungi), to determine the possibility of constructing microorganism-nanoparticle vehicles.

Methods: Hydrocolloids of individual nanoparticles were added to suspensions of S. aureus and C. albicans. Immediately after mixing, the samples were inspected by transmission electron microscopy.

Results: Visualization of the morphologic interaction between the nanoparticles and microorganisms showed that nano-D, which are dielectrics and exhibit a positive zeta potential, were very different from the membrane potentials of microorganisms, and uniformly surrounded the microorganisms, without causing visible damage and destruction of cells. All metal nanoparticles with negative zeta potential had cell damaging properties. Nano-Ag showed the properties of self-organization with the cells, disintegrating the cell walls and cytoplasmic membranes, and releasing a substance (probably cytoplasm) outside the cell. Arrangement of nano-Au with microorganisms did not create a system of self-organization, but instead a "noncontact" interaction between the nanoparticles and microorganisms was observed to cause damage to fungal cells. Nano-Pt caused both microorganisms to release a substance outside the cell and disintegrated the cytoplasmic membrane and cell wall.

Conclusion: Nano-Ag, nano-Au, and nano-Pt (all metal nanoparticles) are harmful to bacteria and fungi. In contrast, nano-D bind closely to the surface of microorganisms without causing visible damage to cells, and demonstrating good self-assembling ability. The results indicate that both microorganisms could be used as potential carriers for nano-D.

Keywords: nanoparticles, diamond, silver, gold, platinum, Staphylococcus aureus, Candida albicans, morphology

\section{Introduction}

Targeted drug transport methods are key techniques being searched for in medicine. Cancer therapy, in particular, requires new technology to deliver drugs precisely, to be nontoxic to other tissues, with the possibility of sustained release of active substances, and to target cells. Microorganisms possess an extraordinary potential to move, survive safely, and settle in precisely programmed regions of the body. ${ }^{1-3}$ Staphylococcus aureus exfoliates epidermal layers and localizes within the skin, ${ }^{4}$ and can also penetrate lungs, bloodstream, joints, and bones. ${ }^{5-10}$ Candida albicans lives on $75 \%$ of the human population and is commonly found in the gastrointestinal tract, oral cavity, and genital area, with no harmful effects. ${ }^{11}$ However, when body resistance is low, as in leukemia, autoimmune deficiency syndrome, or in transplant recipients,
Correspondence: André Chwalibog Department of Basic Animal and Veterinary Sciences, University of Copenhagen, Groennegaardsvej 3 1870 Frederiksberg, Denmark

Tel +453533 3044

Fax +4535333020

Email ac@life.ku.dk submit your manuscript | www.dovepress.com

Dovepress

DOI: $10.2147 /$ IJN.SI 3532 
C. albicans can enter the bloodstream and penetrate different organs, causing serious infections. ${ }^{12-15}$

It is well known that inorganic nanoparticles can act as antibacterial and antifungal agents, and thus have the ability to interact with microorganisms. ${ }^{16-20}$ However, prior to using microorganisms as a mean of transport for bioactive molecules, such as nanoparticles or drugs linked to nanoparticles, it is essential to investigate how to deposit the molecules within microorganisms. It has already been described how Gram-negative bacteria can be used for constructing bacterial ghosts, representing novel advanced delivery and targeting vehicles suitable for the delivery of hydrophobic or water-soluble drugs. ${ }^{2,21}$ Also, in pathogenic fungi, like $C$. albicans, several components associated with the cell wall have been identified to play an important role in fungal-host interactions. $^{22}$

We have previously demonstrated that by simple mixing of nanoparticles of gold and platinum with Salmonella enteritidis and Listeria monocytogenes, a process of selfassembly takes place, but with different morphologic interactions depending on the bacteria and nanoparticles used. ${ }^{23} \mathrm{In}$ the present investigation, other microorganisms and additional nanoparticles were chosen to elucidate further the possibilities for constructing microorganism-nanoparticle vehicles.

Exerting their antibacterial properties, silver nanoparticles (nano-Ag) attach and anchor to the surface of the cell. This interaction causes structural changes and damage, markedly disturbing vital cell functions, such as permeability, causing pits and gaps, depressing the activity of respiratory chain enzymes, and finally leading to cell death. ${ }^{20,24-28}$ Nano-Ag also inhibit yeast growth ${ }^{29,30}$ and have antifungal activity against different Candida species. ${ }^{19,31}$ Results from toxicologic assays have shown no in vitro cytotoxicity of nano-Ag nanoparticles in concentrations sufficient to inhibit microbial growth, ${ }^{18,32}$ but at high concentrations, nano-Ag do exert cytotoxic effects on human mesenchymal stem cells. ${ }^{33}$ More and more results provide evidence for a molecular mechanism of nano-Ag activity, showing that nano-Ag act through reactive oxygen species generation, ${ }^{29}$ leading to activation of proteins and inducing apoptosis via the mitochondrial pathway. ${ }^{34}$ In vivo measurements in chicken embryos and quails demonstrated that hydrocolloids of nano-Ag at the level of $50 \mathrm{ppm}$ did not affect development or cause oxidative DNA damage to embryos $^{35}$ or growth of quails. ${ }^{36}$

Gold nanoparticles (nano-Au) are well established carriers for delivery of double-stranded DNA in gene gun technology. ${ }^{37}$ It has been demonstrated that nano-Au can localize in tumors by passive accumulation, because of the enhanced permeability and retention effect in the leaky vessels of tumors..$^{38-41}$ The process of targeting by nano-Au can minimize treatment durations and side effects of drugs. ${ }^{42,43}$

The antimicrobial activity of platinum has been known since the work of Rosenberg, who reported its inhibitory activity on Escherichia coli division. ${ }^{44}$ Cisplatin and other derivatives synthesized from platinum have been used in cancer treatment, and act by forming adducts with DNA and impairing DNA synthesis and repair. ${ }^{45}$ Recently, analysis of the morphologic effects of interaction between platinum nanoparticles (nano-Pt) and S. enteritidis revealed that nano-Pt were located inside bacteria cells, demonstrating that these cells might be used to deliver nano-Pt and attach active substances to specific targets in the body, as discussed previously. ${ }^{23}$

Diamond nanoparticles (nano-D) are highly biocompatible and nontoxic to human cells. ${ }^{46,47}$ Furthermore, the antioxidative properties of nano-D, via redox pathways, could improve the local environment of treatment areas in the body. ${ }^{48}$ It has also been demonstrated that nano-D inhibit genotoxic and cellular stress at the molecular level in humans. ${ }^{49}$ Nano-D can be applied as drug-sequestering elements, and have exciting prospects, including adjustable and extended time release of the active substance. ${ }^{50}$ Accordingly, in histopathologic and ultrastructural investigations after intratracheal administration of nano-D in mice, no adverse effects in the lungs were noticed. Furthermore, no lipid peroxidation of the lung was observed. ${ }^{51}$

In a previous paper, ${ }^{23}$ we indicated that shortly after mixing nano-Pt with $S$. enteritidis, nano-Pt penetrated bacterial cells and remained inside the bacteria, even after washing and centrifugation, and that the average number of bacterial cells with nano-Pt did not change after prolonged incubation. These observations indicate that the complexes, visualized shortly after mixing, are stable, and that the interaction can be observed directly in real time and with minimized chemical (handling of the sample) interference. Consequently, in the present investigation, the characteristics of self-assembly were observed immediately after mixing nanoparticles with microorganisms. The objective was to identify additional candidates for constructing microorganism-nanoparticle vehicles to deliver active substances to specific targets in the body. The examined compounds were $S$. aureus and C. albicans, together with nanoparticles of diamond, silver, gold, and platinum.

\section{Materials and methods Nanoparticles}

Diamond nanoparticles were obtained from the Biomedical Engineering Division, Technical University of Łódź. Nano-D 
was produced by the method described by Danilenko ${ }^{52}$ with modification of ampoule-free synthesis with explosions in the explosion chamber. Graphite was placed directly into a cylindrical charge consisting of a TNT-hexogen mixture TG40; the charge was enveloped in a water jacket to suppress graphitization and to reduce the unloading rate of the synthesized diamond. ${ }^{53}$ For experiments with microorganisms, nano-D was suspended in Milli-Q water (Millipore, Billerica, $\mathrm{MA})$ at a concentration of $50 \mathrm{ppm}$. Shape and size of nanoparticles were evaluated using a JEM-2000EX transmission electron microscope (TEM) at $200 \mathrm{keV}$ (JEOL, Tokyo, Japan), showing that the size of particles ranged from 2 to $10 \mathrm{~nm}$ (Figure 1).

Hydrocolloids of silver, gold, and platinum nanoparticles (50 ppm) obtained from Nano-Tech (Warsaw, Poland) were produced by an electric nonexplosive patented method (Polish Patent 3883399) from high purity metals (99.9999\%) and high purity demineralized water. Shape and size of nanoparticles were inspected by TEM (Figure 1), showing that the diameter of the particles was 2-35 nm for Ag, 2-29 nm for $\mathrm{Au}$, and 2-19 $\mathrm{nm}$ for Pt.

The zeta potential of hydrocolloids of nanoparticles and microorganisms was measured by the electrophoretic light-scattering method, ${ }^{54}$ using a Zetasizer Nano ZS, model ZEN3500 (Malvern Instruments, Worcestershire, UK). Each sample was measured after 120 seconds of stabilization at $25^{\circ} \mathrm{C}$, in 20 replicates. The mean zeta potential was $-9.2 \mathrm{mV}$ (nano- $\mathrm{Ag}$ ), $-1.9 \mathrm{mV}$ (nano- $\mathrm{Au}$ ), $-9.6 \mathrm{mV}$ (nano-Pt), and $+27 \mathrm{mV}$ (nano-D). The microorganisms had zeta potentials between -20 and $-27 \mathrm{mV}$.

\section{Microorganisms}

Strains were obtained from LGC Standards (Lomianki, Poland). Bacteria strain S. aureus ATCC 25923 was grown on trypto-casein-soy agar (BioRad, San Francisco, CA). Fungi strain C. albicans ATCC 24433 was grown on Sabouraud agar (BTL, Lódź, Poland). Microorganisms were gently washed out from the agar using sterile distilled water. To remove the liquid remains of the medium, bacteria were centrifuged at $4000 \mathrm{rpm}$ for five minutes using an Eppendorf MiniSpin centrifuge and the sediment (pellet) was resuspended in Milli-Q water. To calculate the exact number of microorganisms in the suspension, the optical density at $600 \mathrm{~nm}$ (OD600) was estimated by spectrophotometer (Helios Epsilon, Unicam; Thermo Spectronic, Madison, WI), and serial dilutions of the suspension were prepared. One milliliter of each dilution was transferred

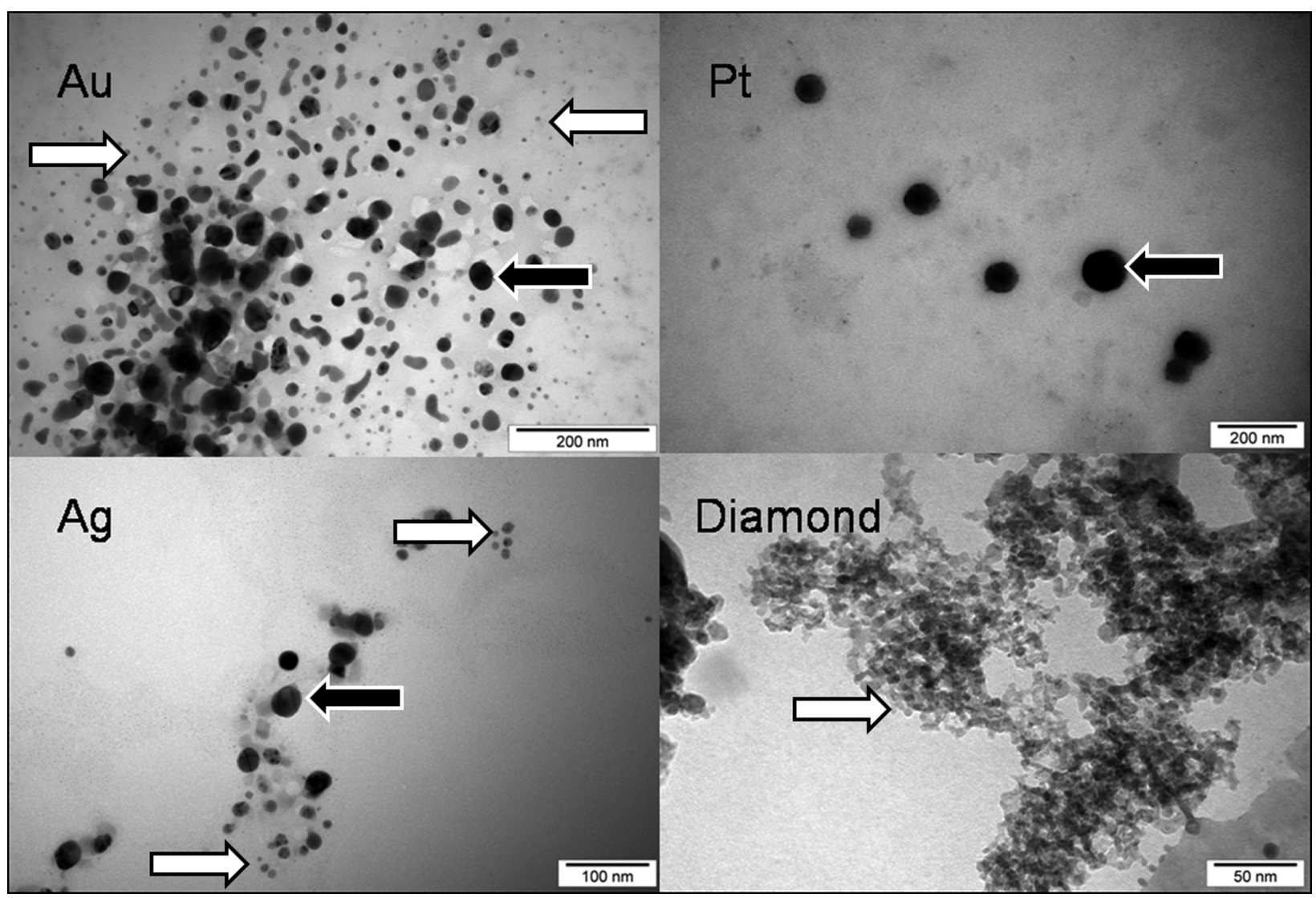

Figure I Nanoparticles of diamond, silver, gold, and platinum. 
to Petri dishes with agar. After 24 hours of incubation at $37^{\circ} \mathrm{C}$, the number of colonies was estimated. According to the results of triple measurements, the density of microbial suspension OD600 $=0.140$ corresponded to $1.95 \times 108 \mathrm{cfu} / \mathrm{mL}$ and at OD600 $=0.182$ corresponded to $7.3 \times 107 \mathrm{cfu} / \mathrm{mL}$ for $S$. aureus and C. albicans, respectively.

\section{Method of observation}

Hydrocolloids of each kind of nanoparticle $(200 \mu \mathrm{L})$ were separately added to the microorganism suspensions $(200 \mu \mathrm{L})$. Control samples of microorganisms were treated with Milli-Q water. The samples were gently mixed for 15 minutes and then droplets of samples were put on Formvar-coated 300 mesh Cu grids (Agar Scientific Ltd, Stansted, UK). In this way, the inspected object was observable after a very short time of interaction of nanoparticles with the living microorganisms. The samples were dried at room temperature, in sterile conditions, and observed using a JEM-2000EX TEM at $200 \mathrm{keV}$ (JEOL). The applied voltage was chosen to avoid any damage to the sample. The method developed enabled direct observation of the initial interface between nanoparticles and microorganisms, particularly including visualization of small amounts of a substance excreted from the microorganisms.

\section{Results}

Examination of the control microorganisms indicated some changes caused by the applied methods (centrifugation, Milli-Q water, drying), but did not show any toxicologic or destructive alteration (Figure 2).

The morphology of interaction between nano-D and $S$. aureus is presented in Figure 3. Nano-D were attached nonspecifically to the cell wall, showing affinity for the peptidoglycan layer. Nano-D could be seen also within the cell and cell wall. When nano-D interacted with C. albicans, it was observed that diamond also attached and surrounded the cells very closely. Nano-D was gathered by the released substance, probably cytoplasm (Figure 4).

The image of morphologic effects of nano-Ag and $S$. aureus assembling (Figure 5) indicates that nano-Ag were located at given points on the bacterial cell. They caused gaps and made the cell release some of the substances to which they adsorbed. The morphologic effect of interaction between nano-Ag and C. albicans was quite similar (Figure 6). Cells became distorted, and nano-Ag disintegrated and disrupted the cell wall and cytoplasmic membrane and a substence (probably cytoplasm) was leaking from the fungi cells.

Nano-Au did not surround $S$. aureus but were trapped within the biofilm produced by the cell (Figure 7). Nano-Au disintegrated the cell wall and the cytoplasmic membrane of C. albicans. However, they were not seen around the fungal cells. Cells and their clusters were surrounded by released inhomogeneous matter, containing droplets of different electron density. Nano-Au appeared to be attached to a filamentous substance, probably excreted from the disrupted cells (Figure 8).

Nano-Pt caused $S$. aureus to release substances and similarly disintegrated the cytoplasmic membrane and the cell wall, as did the other metal nanoparticles (Figure 9). Nano-Pt disintegrated the cell wall and cytoplasmic membrane also in C. albicans and stimulated release of some substances, which leaked from the cells (Figure 10). The cell wall seemed to be loosened and separated from the cytoplasmic membrane. Interestingly, the nanoparticles appeared to be surrounded by matter different from the released substance.

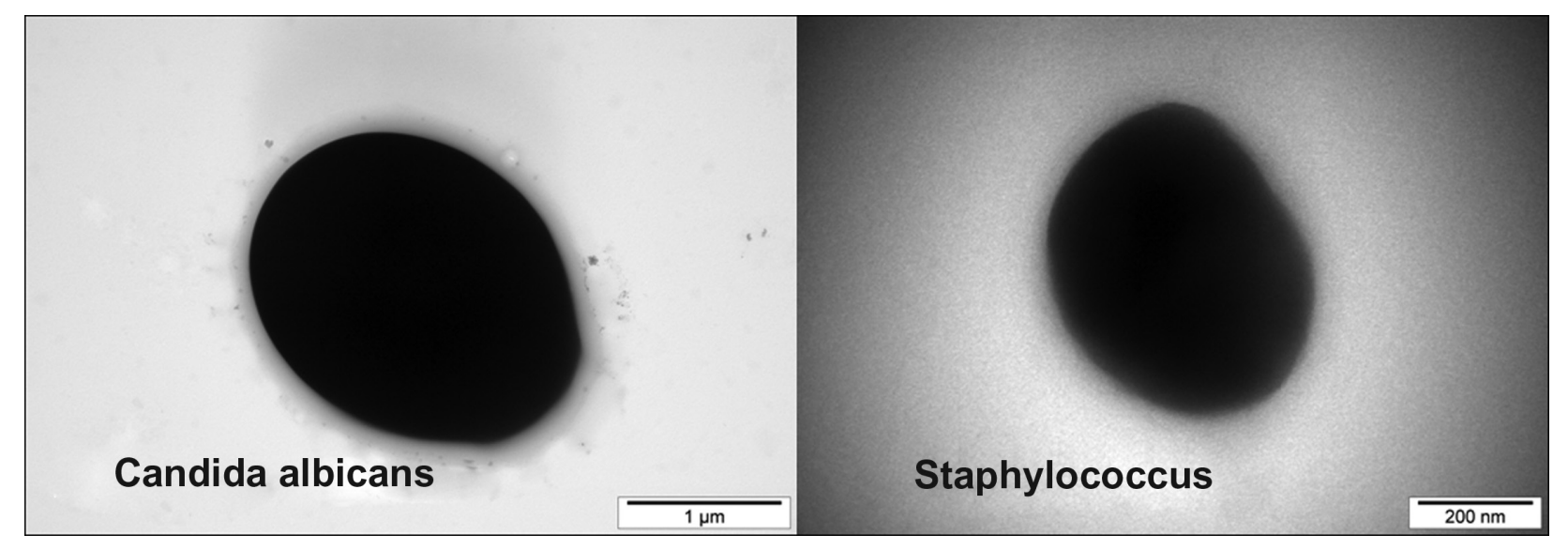

Figure 2 Staphylococcus aureus and Candida albicans. None of the toxicologic or destructive effects of the procedure can be seen. 


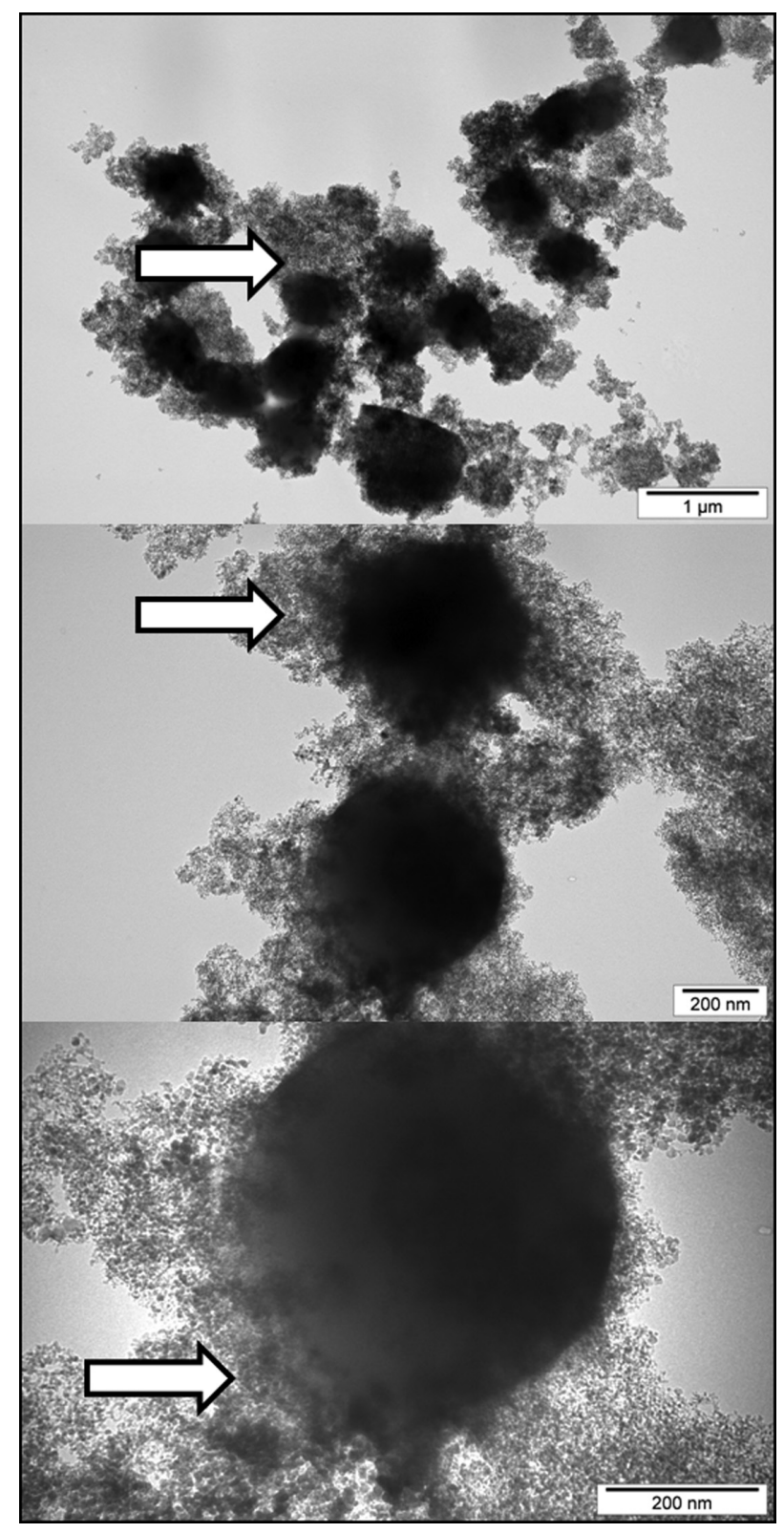

Figure 3 Interaction between Staphylococcus aureus and diamond nanoparticles. Arrows indicate nanoparticles nonspecifically attached to the microorganisms.

\section{Discussion}

In the present investigation, different chemical and physical properties of diamond and metal nanoparticles were confirmed when they came into contact with living organisms. They exhibited various effects on bacteria and fungi.

We could observe a clear link between zeta potential and the electron structure of the nanoparticles and their interaction with microorganisms. Nano-D are dielectrics and exhibit a positive zeta potential, being very different from the membrane potential of microorganisms, and uniformly surrounded the microorganisms, without causing visible damage and destruction of the cells (Figures 3 and 4).

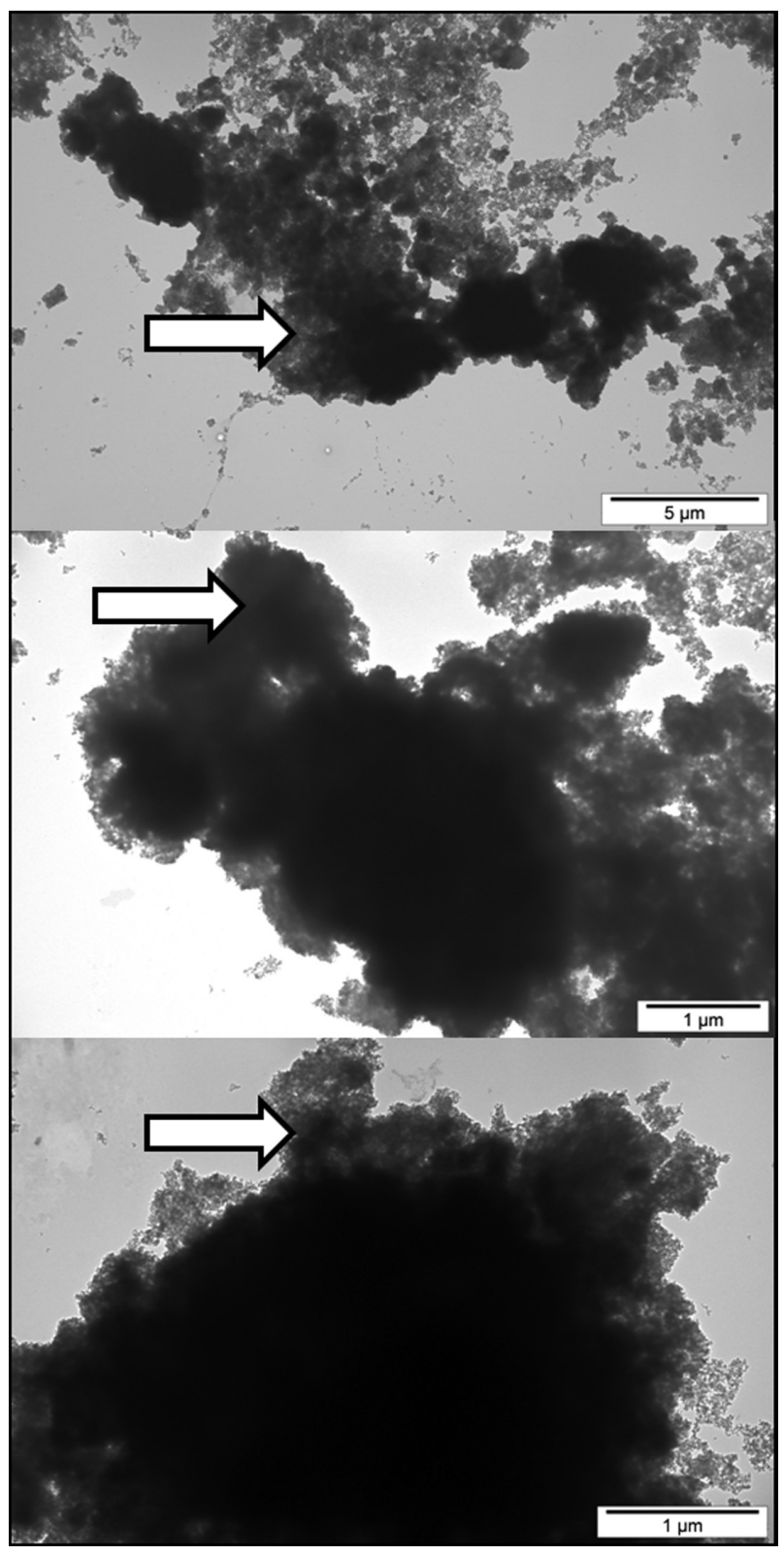

Figure 4 Interaction between Candida albicans and diamond nanoparticles. Arrows indicate nanoparticles surrounding cells very closely.

In the case of $C$. albicans, glucan and chitin, both microfibrillar polysaccharides, are cellular components that confer rigidity to the overall cell wall structure, and appear to be more concentrated in the inner cell wall layer, adjacent to the plasma membrane. In the outermost cell wall layer, proteins and mannoproteins appear to predominate, ${ }^{55}$ and nano-D could possibly bind them closely, without visible cell destruction.

All metal nanoparticles with negative zeta potential, ie, less than the zeta potential of bacterial cells, showed celldamaging properties. However, their behaviors were different, in that silver showed the properties of self-organization 


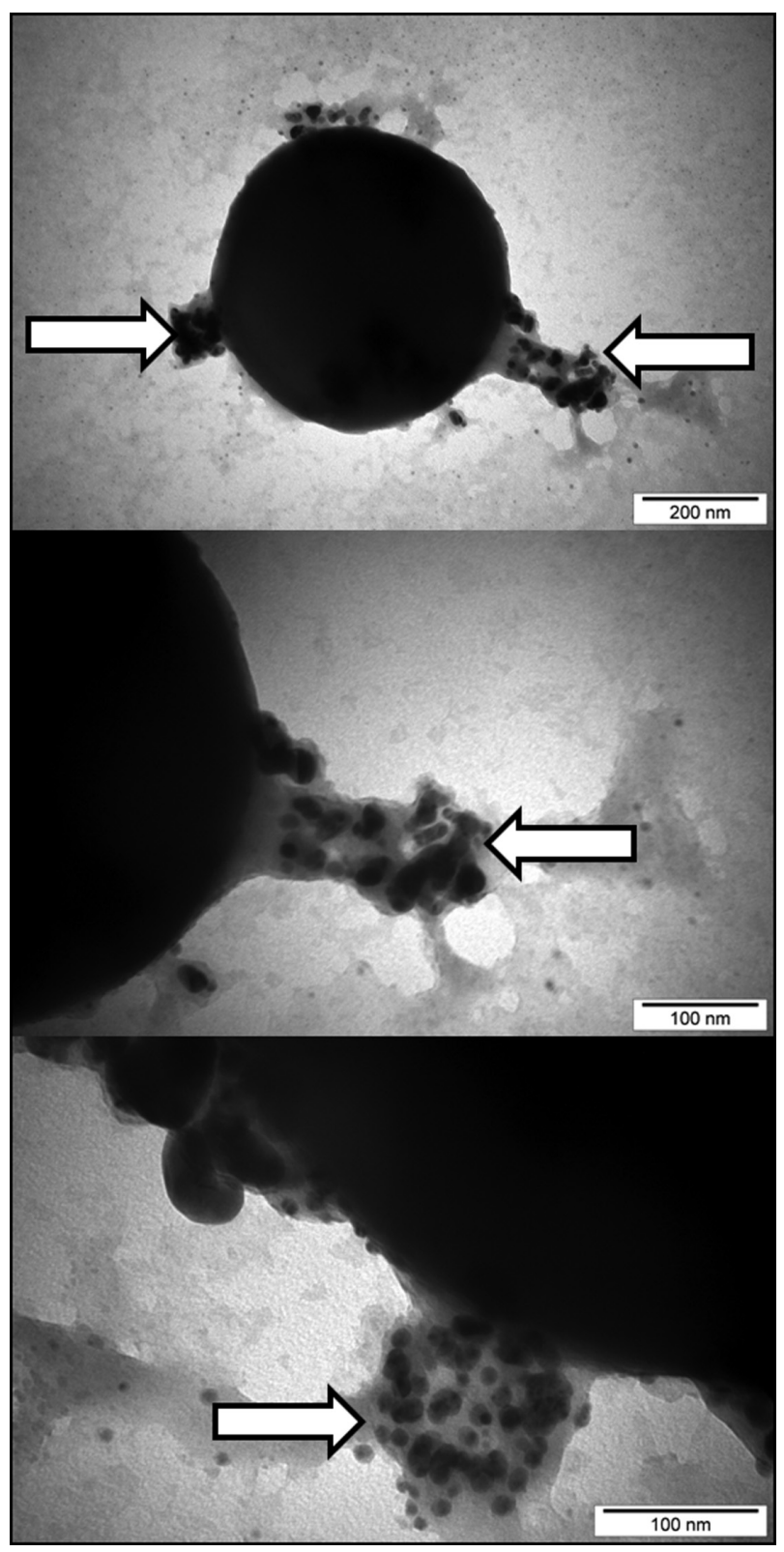

Figure 5 Interaction between Staphylococcus aureus and silver nanoparticles. Arrows indicate nanoparticles located at specific points on the cells, attached to the substance released by microorganisms.

with the cells, disintegrating the cell walls and cytoplasmic membranes, and releasing a substance (probably cytoplasm) outside the cell. The released substance was strongly connected with nano-Ag, indicating possible chemisorption of the substance to nano-Ag (Figure 5).

Nano-Ag, when evaluated for their antimicrobial activity against Gram-positive and Gram-negative bacteria, showed high antibacterial activity against both types of bacteria, including highly multiresistant strains, such as $S$. aureus. ${ }^{56,57}$ Antifungal activity of nano- $\mathrm{Ag}^{29-31,56}$ has been also suggested in the present investigation. The results suggest that nano- $\mathrm{Ag}$

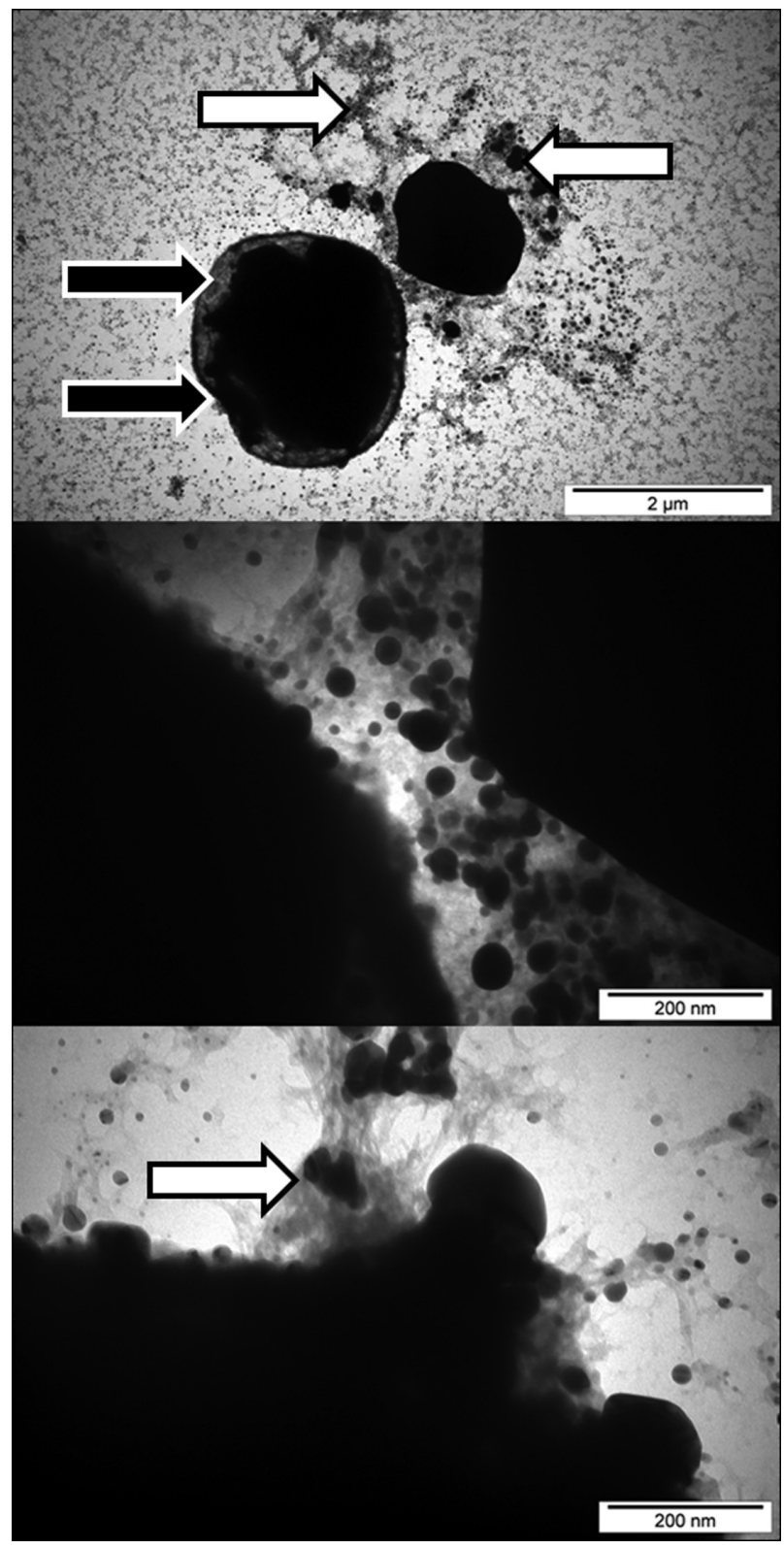

Figure 6 Interaction between Candida albicans and silver nanoparticles. White arrows indicate nanoparticles attached to the substance released by microorganisms. Black arrows indicate distorted cells, a disintegrated cell wall, and cytoplasmac membrane.

may exert a fungicidal activity by destroying cell membrane integrity (Figure 6). Other results ${ }^{30}$ have also shown that fungal cells treated with nano-Ag show significant damage, characterized by the formation of a pit in their cell walls and pores in their plasma membrane.

In the case of nano-Pt, it is difficult to assess whether self-assembling occurred, since activity of Pt was violent, causing an outflow of a substance outside the cells, probably due to damaged walls and cell membranes (Figures 9 and 10). This is in agreement with our previous results regarding selfassembling between nano-Pt and $S$. enteritidis, showing that 


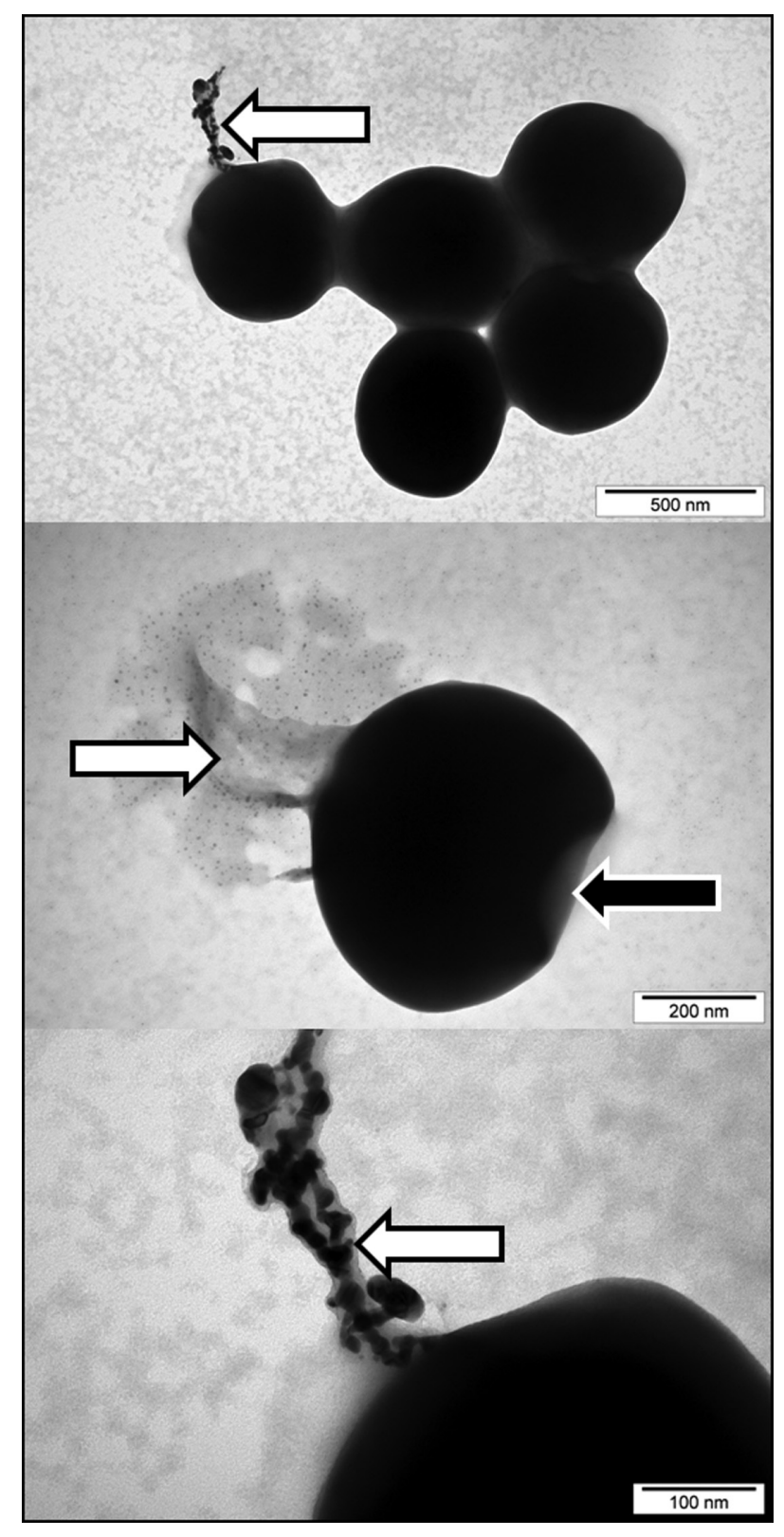

Figure 7 Interaction between Staphylococcus aureus and gold nanoparticles. White arrows indicate nanoparticles trapped by the biofilm and the substance released by cells. Black arrow indicates distorted cell wall.

nano-Pt disintegrated bacterial cell walls and cytoplasmic membranes. ${ }^{23}$

Compared with nano-Ag and nano-Pt, nano-Au showed different effects on bacteria and fungi cells. Arrangement of nano-Au with microorganisms did not create a system of self-organization. However, a "noncontact" interaction between nanoparticles and microorganisms caused damage to fungal cells (Figure 8) and probably a defensive reaction on the part of the bacterial cells (Figure 7). The impact of gold could be explained by ion emission from the nanoparticles in an aqueous environment. Moreover, it is very interesting

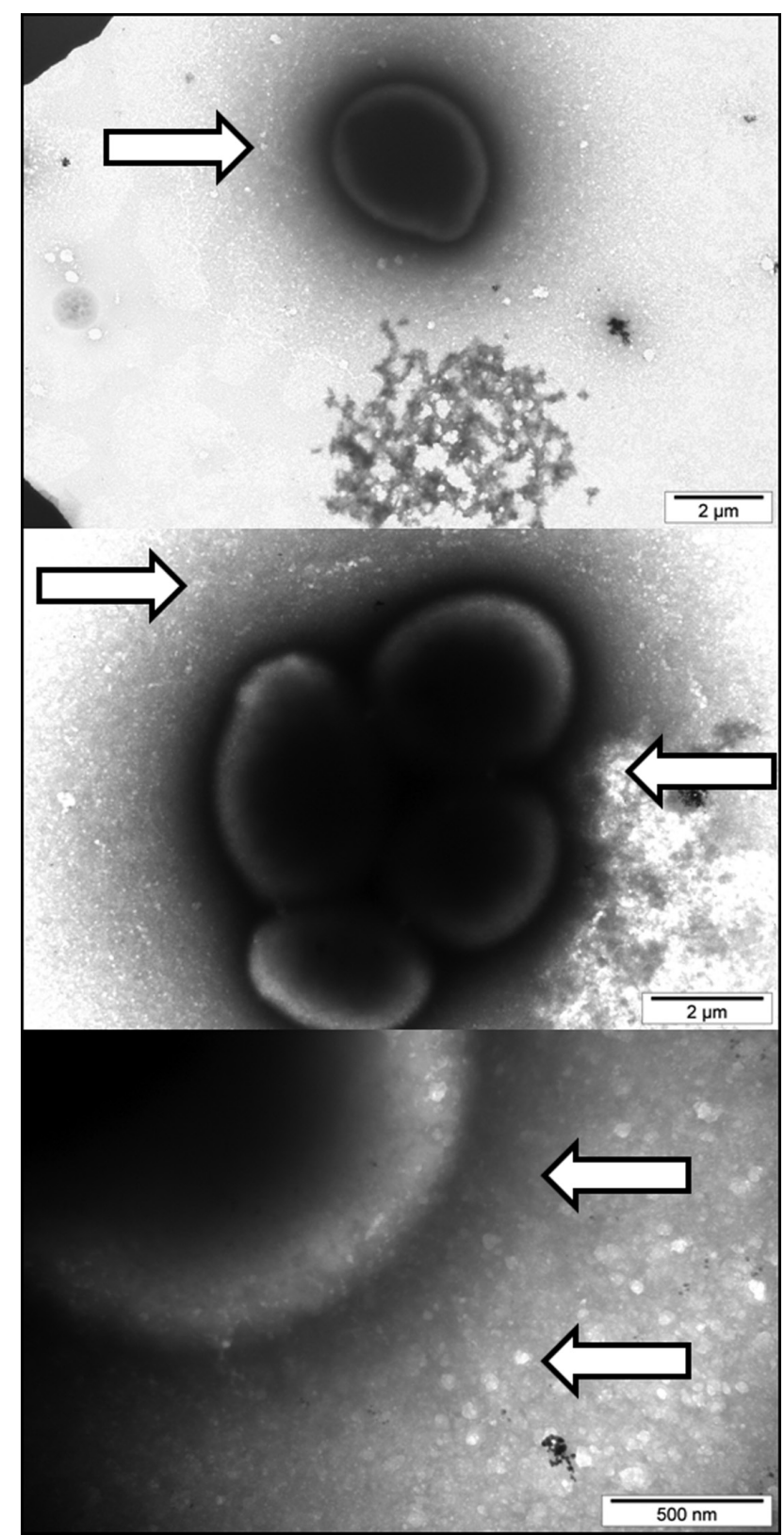

Figure 8 Interaction between Candida albicans and gold nanoparticles. Arrows indicate the substance of different electron density released by cells.

that the interaction with nano-Au is not the same as with nano-Ag. It could be expected that interactions occurring would be similar, because both kinds of nanoparticles should bind the same chemically active groups on the surface of the cell. However, the interaction observed was different for these two kinds of nanoparticles.

The present observations indicate that the contact between metal nanoparticles (nano-Ag, nano-Au, and nano-Pt) and microorganisms promote chemical interactions that are harmful to the microorganism. However, dielectric nano-D, with high, positive zeta potential, appear to be 


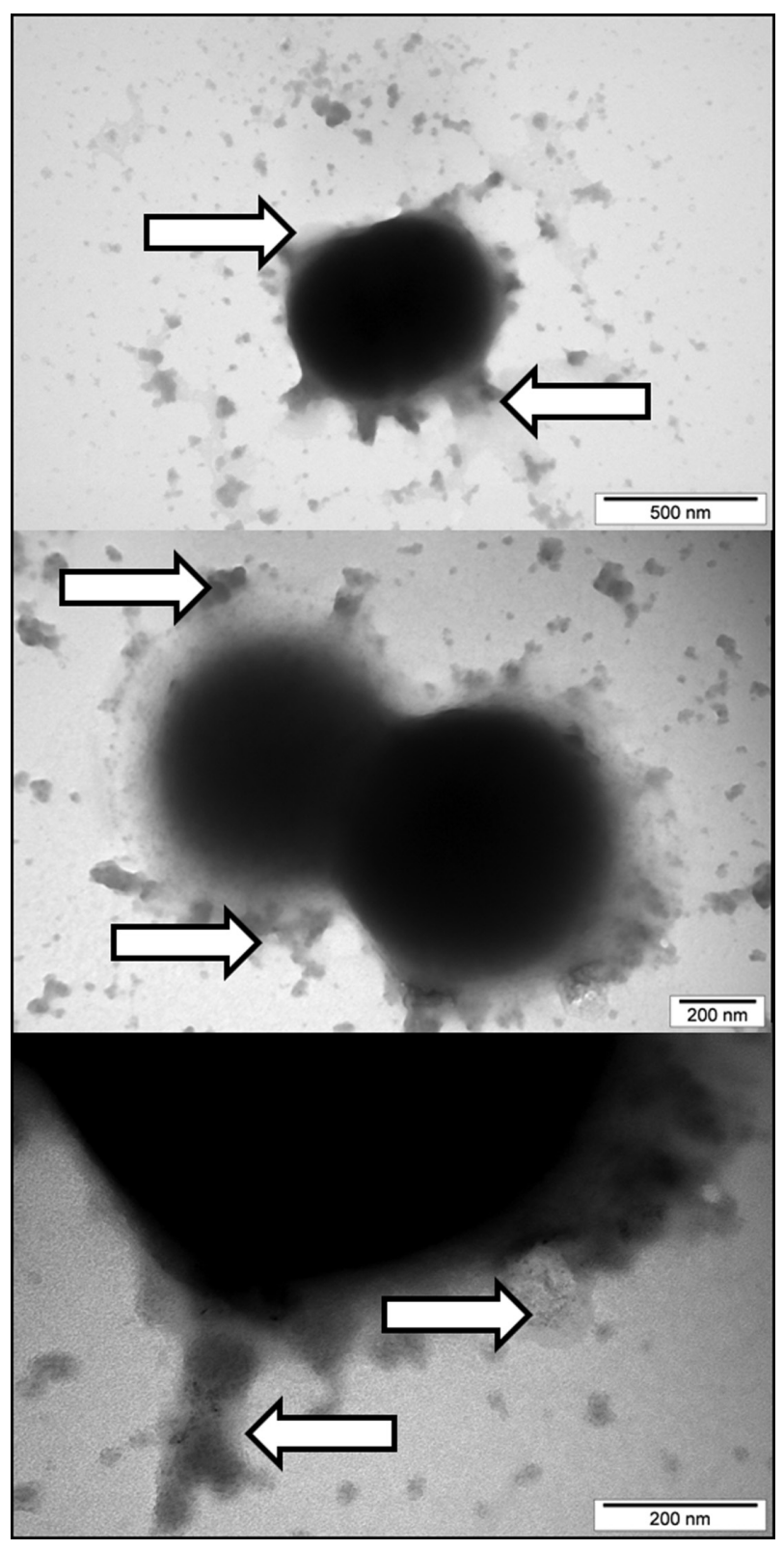

Figure 9 Interaction between Staphylococcus aureus and platinum nanoparticles. Arrows indicate nanoparticles and the substance released by cells.

chemically nonaggressive, and create consistent systems of self-assembly with microorganisms. This observation could be an important guideline for selection of applications of nanoparticles as antimicrobial compounds and/or as carriers of active medical substances.

The application of TEM visualization provides an extraordinary opportunity for the morphologic evaluation of ongoing interactions between microorganisms and nanoparticles. Unfortunately, using this technique, it was not possible to identify chemical bonds between the two components. As mentioned earlier, the interface between them is very specific as well for the types of microorganisms and

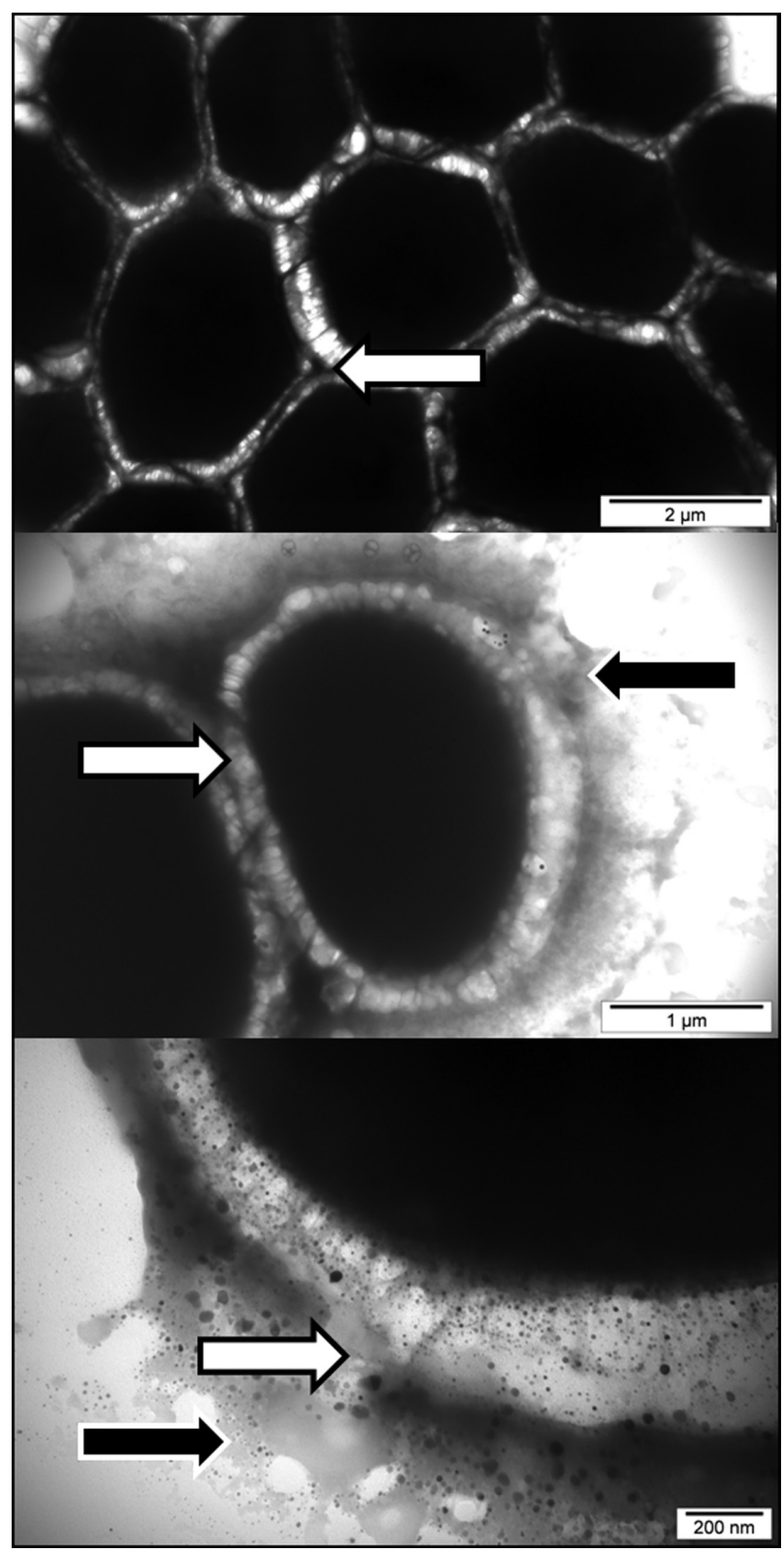

Figure 10 Interaction between Candida albicans and platinum nanoparticles. Black arrows indicate nanoparticles surrounded by the released substance. White arrows indicate the cell wall loosened and separated from the membrane or disrupted.

nanoparticles. It can only be speculated what kind of microorganism envelope is involved in the interaction, and this needs further investigation using specific staining methods.

\section{Conclusion}

Nano-Ag, nano-Au, and nano-Pt (metal nanoparticles) are harmful to bacteria and fungi. Nano-Ag attach specifically to the microbial cell wall, evoke the release of a substance from the microorganisms, and bind to it. Nano-Au act in a "noncontact" way, stimulate biofilm production, and aggregate within this biofilm. Nano-Pt damage cell walls and cause the release of a substance leaking from the cells. 
Unlike metal nanoparticles, nano-D bind closely to the surface of the microorganisms without causing visible damage to the cells, indicating good self-assembling ability. The results indicate that both microorganisms could potentially be used as carriers for nano-D.

\section{Acknowledgments}

This work was supported by grants including "New, multifunctional nanopowder of carbon" 357/ERA-NET 2008 2011, Danish Agency for Science Technology and Innovation: 2106-08-0025 and MNiSW N31104931/3849, Poland.

\section{Disclosure}

The authors declare that they have no competing interests in this work.

\section{References}

1. Paukner S, Kohl G, Jalava K, Lubitz W. Sealed bacterial ghosts novel targeting vehicles for advances drug delivery of water-soluble substances. J Drug Target. 2003;11:151-161.

2. Paukner S, Stiedl T, Kudela P, Bizik J, Al Laham F, Lubitz W. Bacterial ghosts as a novel advanced targeting system for drug and DNA delivery. Expert Opin Drug Deliv. 2006;3:11-22.

3. Akin D, Sturgis J, Ragheb K, et al. Bacteria-mediated delivery of nanoparticles and cargo into cells. Nat Nanotechnol. 2007;2:441-449.

4. Lowy FD. Staphylococcus aureus infections. N Engl J Med. 1998;339: $520-532$.

5. Cunningham R, Cockayne A, Humphreys H. Clinical and molecular aspects of the pathogenesis of Staphylococcus aureus bone and joint infections. J Med Microbiol. 1996;44:157-164.

6. Renders NHM, van Belkurn A, Overbeek SE, Mouton JW, Hrbrugh HA. Molecular epidemiology of Staphylococcus aureus strains colonizing the lungs of related and unrelated cystic fibrosis patients. Clin Microbiol Infect. 1997;3:216-221.

7. Koort JK, Makinen TJ, Knuuti J, Jalava J, Aro HT. Comparative 18FFDG PET of experimental Staphylococcus aureus osteomyelitis and normal bone healing. J Nucl Med. 2004;45:1406-1411.

8. Elizur A, Orscheln RC, Ferkol TW, et al. Panton-Valentine leukocidinpositive methicillin-resistant Staphylococcus aureus lung infection in patients with cystic fibrosis. Chest. 2007;131:1718-1725.

9. Amsterdam D, Coombs G, Dowzicky M. Antimicrobial susceptibility of bloodstream isolates of Staphylococcus aureus: Global results from the tigecycline evaluation and surveillance trial, 2004-2008. Am J Infect Dis. 2010;6:1-7.

10. Big C, Malani PN. Staphylococcus aureus bloodstream infections in older adults: Clinical outcomes and risk factors for in-hospital mortality. J Am Geriatr Soc. 2010;58:300-305.

11. MacCallum D. Candida albicans: New insight in infection, disease, and treatment. In: Kavanagh K, editor. New Insight in Medical Mycology. Berlin, Germany: Springer-Verlag; 2007.

12. Stinnett EA, Childers NK, Wright JT, Rodu BK, Bradley EL Jr. The detection of oral Candida in pediatric leukemia patients. Pediatr Dent. 1992;14:236-239.

13. Cantu J. Hepatosplenic candidiasis in patients with acute leukemia. Internet J Emerg Intens Care Med. 2005;8(2).

14. Dongari-Bagtzoglou A, Dwivedi P, Ioannidou E, et al. Oral Candida infection and colonization in solid organ transplant recipients. Oral Microbiol Immunol. 2009;24:249-254.

15. Basu S, Chakraborty D, Das S. Susceptibility of Candida species isolated from HIV infected and newborn candidaemia patients to amphotericin B. OnLine J Biol Sci. 2010;10:109-113.
16. Hernandez-Sierra JF, Ruiz F, Pena DC, et al. The antimicrobial sensitivity of Streptococcus mutans to nanoparticles of silver, zinc oxide and gold. Nanomedicine NBM. 2008;4:237-240.

17. Dror-Ehre A, Mamane H, Belenkova T, Markovich G, Adin A. Silver nanoparticle - E. coli colloidal interaction in water and effect on E. coli survival. J Colloid Interface Sci. 2009;339:521-526.

18. Eby DM, Shaeublin NM, Farrington KE, Hussain SM, Johnson GR. Lysozyme catalyzes the formation of antimicrobial silver nanoparticles. ACS Nano. 2009;3:984-994.

19. Panacek A, Kolar M, Vecerova R, et al. Antifungal activity of silver nanoparticles against Candida spp. Biomaterials. 2009;30:6333-6340.

20. Rai M, Yadav A, Gade A. Silver nanoparticles as a new generation of antimicrobials. Biotechnol Adv. 2009;27:76-83.

21. Beachey EH. Bacterial adherence: Adhesin-receptor interactions mediating the attachment of bacteria to mucosal surfaces. J Infect Disease. 1881;143:325-345.

22. Munro C. Candida albicans cell wall mediated virulence. In: Ashbee HR, Bignell EM, editors. Pathogenic Yeasts. The Yeast Handbook. Berlin, Germany: Springer-Verlag; 2010.

23. Sawosz E, Chwalibog A, Szeliga J, et al. Visualization of gold and platinum nanoparticles interacting with Salmonella enteritidis and Listeria monocytogenes. Int J Nanomed. 2010;5:631-637.

24. Morones JR, Elechiguerra JL, Camacho A, et al. The bactericidal effect of silver nanoparticles. Nanotechnology. 2005;16:2346-2353.

25. Pal S, Tak YK, Song JM. Does the antibacterial activity of silver nanoparticles depend on the shape of the nanoparticle? A study of the Gram-negative bacterium Escherichia coli. Appl Environ Microbiol. 2007;73:1712-1720.

26. Shrivastava S, Bera T, Roy A, Singh G, Ramachandrarao P, Dash D. Characterization of enhanced antibacterial effects of novel silver nanoparticles. Nanotechnology. 2007;18:225103-225111.

27. Li W-R, Xie X-B, Shi Q-S, Zeng H-Y, Ou-Yang Y-S, Chen Y-B. Antibacterial activity and mechanism of silver nanoparticles on Escherichia coli. Appl Microbiol Biotechnol. 2010;85:1115-1122.

28. Sharma VK, Yngard RA, Lin Y. Silver nanoparticles: Green synthesis and their antimicrobial activities. Adv Colloid Interface Sci. 2009; 145:83-96.

29. Kim JS, Kuk E, Yu KN, et al. Antimicrobial effects of silver nanoparticles. Nanomedicine NBM. 2007;3:95-101.

30. Kvitek L, Vanickova M, Panacek A, et al. Initial study on the toxicity of silver nanoparticles (NPs) against Paramecium caudatum. J Phys Chem. 2009;113:4296-4300.

31. Kim K-J, Sung WS, Suh BK, et al. Antifungal activity and mode of action of silver nano-particles on Candida albicans. Biometal. 2009; 22:235-242.

32. Alt V, Bechert T, Steinrucke P, et al. An in vitro assessment of the antibacterial properties and cytotoxicity of nanoparticulate silver bone cement. Biomaterials. 2004;25:4383-4391.

33. Greulich C, Kittler S, Epple M, Muhr G, Koller M. Studies on the biocompatibility and the interaction of silver nanoparticles with human mesenchymal stem cells (hMSCs). Langenbecks Arch Surg. 2009;394:495-502.

34. Hsin Y-H, Chen C-F, Huang S, et al. The apoptotic effect of nanosilver is mediated by a ROS- and JNK-dependent mechanism involving the mitochondrial pathway in NIH3T3 cells. Toxicol Lett. 2008;179:130-139.

35. Sawosz E, Binek M, Grodzik M, et al. Influence of hydrocolloidal silver nanoparticles on gastrointestinal microflora and morphology of enterocytes of quails. Arch Anim Nutr. 2007;61:444-451.

36. Sawosz E, Grodzik M, Zielinska M, Niemiec T, Olszańska B, Chwalibog A. Nanoparticles of silver do not affect growth, development and DNA oxidative damage in chicken embryos. Arch Geflügelk. 2009;73:208-213.

37. Niemeyer CM. Nanoparticles, proteins, and nucleic acids: Biotechnology meets materials science. Angew Chem Int Ed. 2001;40:4128-4158.

38. Connor EE, Mwamuka J, Gole A, Murphy CJ, Wyatt MD. Gold nanoparticles are taken up by human cells but do not cause acute cytotoxicity. Small. 2005;1:325-327. 
39. Thomas M, Klibanov AM. Conjugation to gold nanoparticles enhances polyethylenimine's transfer of plasmid DNA into mammalian cells. Proc Natl Acad Sci U S A. 2003;100:9138-9143.

40. Tkachenko AG, Xie H, Liu Y, et al. Cellular trajectories of peptidemodified gold particle complexes: Comparison of nuclear localization signals and peptide transduction domains. Bioconjug Chem. 2004;15: $482-490$.

41. Mukherjee P, Bhattacharya R, Bone N, et al. Potential therapeutic application of gold nanoparticles in B-chronic lymphocytic leukemia (BCLL): Enhancing apoptosis. J Nanobiotechnology. 2007;5:4

42. Zheng Y, Sache L. Gold nanoparticles enhance DNA damage induced by anti-cancer drugs and radiation. Radiat Res. 2009;172:114-119.

43. Cheng Y, Samia AC, Li J, Kenney ME, Resnick A, Burda C. Delivery and efficacy of a cancer drug as a function of the bond to the gold nanoparticle surface. Langmuir. 2010;26:2248-2255.

44. Rosenberg B, van Camo R, Krigas T. Inhibition of cell division in Escherichia coli by electrolysis products from platinum electrode. Nature. 1965;205:698-699.

45. Desoize B, Madoulet C. Particular aspects of platinum compounds used at present in cancer treatment. Crit Rev Oncol Hematol. 2002;42: 317-325.

46. Schrand AM, Huang H, Carlson C, et al. Are diamond nanoparticles cytotoxic? J Phys Chem B. 2007;111:2-7.

47. Lam R, Ho D. Nanodiamonds as vehicles for systemic and localized drug delivery. Expert Opin Drug Deliv. 2009;6:883-895.

48. Bakowicz K. Bioactivity of Diamond. PhD Thesis. Technical University of Lodz: Poland; 2003.
49. Bakowicz-Mitura K, Bartosz G, Mitura S. Influence of diamond powder particles on human gene expression. Surf Coat Tech. 2007;201: 6131-6135.

50. Lam R, Chen M, Pierstorff E, Huang H, Osawa E, Ho D. Nanodiamondembedded microfilm devices for localized chemotherapeutic elution. ACS Nano. 2008;2:2095-2102.

51. Yuan Y, Wang X, Jia G, et al. Pulmonary toxicity and translocation of nanodiamonds in mice. Diamond and Related Materials. 2010;19:291-299.

52. Danilenko VV. Synthesizing and Sintering of Diamond by Explosion. Moscow, Russia: Energoatomizdat; 2003.

53. Mitura S, Mitura K, Niedzielski P, Louda P, Danilenko V. Nanocrystalline diamond, its synthesis, properties and applications. J Achieve Mater Manuf Eng. 2006;16:9-16.

54. Schärtl W, editor. Light Scattering from Polymer Solutions and Nanoparticle Dispersions. Berlin, Germany: Springer-Verlag; 2007.

55. Chaffin WL, Lopez-Ribot JL, Casanova M, Gozalbo D, Martinez JP. Cell wall and secreted proteins of Candida albicans: Identification, function, and expression. Microbiol Mol Biol Rev. 1998;62:130-180.

56. Panacek A, Kvitek L, Prucek R, et al. Silver colloid nanoparticles: Synthesis, characterization and their antibacterial activity.JPhys Chem B. 2006;110:16248-16253.

57. Martinez-Castanon GA, Nino-Martinez N, Martinez-Gutierrez F, Martinez-Mendoza JR, Ruiz F. Synthesis and antibacterial activity of silver nanoparticles with different sizes. J Nanopart Res. 2008;10: 1343-1348.
International Journal of Nanomedicine

\section{Publish your work in this journal}

The International Journal of Nanomedicine is an international, peerreviewed journal focusing on the application of nanotechnology in diagnostics, therapeutics, and drug delivery systems throughout the biomedical field. This journal is indexed on PubMed Central, MedLine, CAS, SciSearch $®$, Current Contents ${ }^{\circledR} /$ Clinical Medicine,

\section{Dovepress}

Journal Citation Reports/Science Edition, EMBase, Scopus and the Elsevier Bibliographic databases. The manuscript management system is completely online and includes a very quick and fair peer-review system, which is all easy to use. Visit http://www.dovepress.com/ testimonials.php to read real quotes from published authors. 